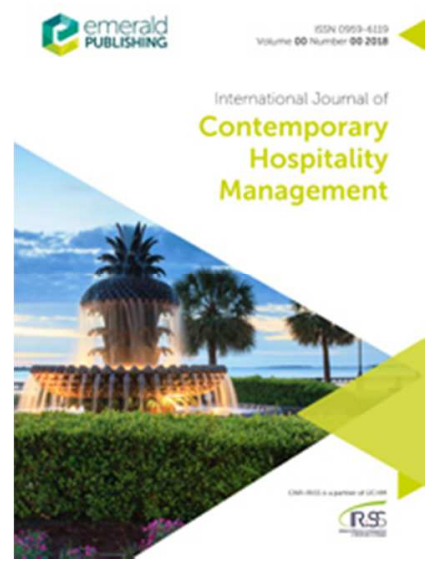

\title{
Human Trafficking in Hotels: An 'Invisible' Threat for a Vulnerable Industry
}

\begin{tabular}{|r|l|}
\hline Journal: & International Journal of Contemporary Hospitality Management \\
\hline Manuscript ID & IJCHM-04-2017-0213.R2 \\
\hline Manuscript Type: & Original Article \\
\hline Keywords: & Crime, Human Trafficking, Hotels, MAVUS, Vulnerability \\
\hline \multicolumn{2}{|c}{} \\
\hline
\end{tabular}

SCHOLARONE ${ }^{\mathrm{m}}$

Manuscripts 


\section{Human Trafficking in Hotels: An 'Invisible' Threat for a Vulnerable Industry}

Submitted: 12 April 2017

$1^{\text {st }}$ Revision: 18 August 2017

$2^{\text {nd }}$ Revision: 20 October 2017

Accepted: 11 November 2017

Purpose: To identify and analyse the hotel sector's vulnerabilities that human traffickers exploit in order to use hotels as conduits for trafficking in human beings (THB).

Design/methodology/approach: Using the MAVUS framework of sector vulnerability analysis, the study adopted a qualitative approach employing environmental scanning and semi-structured key stakeholder interviews in three European countries: UK, Finland and Romania.

Findings: The study identifies the types of THB occurring within the industry and the specific macro-, meso- and micro-level factors that increase hotel vulnerability to trafficking for sexual exploitation, labour exploitation or both.

Research limitations/implications: Given the sensitivity of the topic the number of interviewees is limited as is the generalisability of the findings.

Practical implications: The framework developed serves as a practical tool for independent or chain-affiliated hotels to use to assess their vulnerability to human trafficking for both sexual and labour exploitation.

Social implications: The framework will assist hotel professionals to assess their vulnerability to human trafficking and identify specific and proactive measures to combat this crime within their business.

Originality/value: This is the first study to empirically explore human trafficking in the hotel sector and to apply an integrated theoretical lens to examine macro-, meso- and micro-level sector vulnerabilities to a crime. It contributes to our understanding of why hotels are vulnerable to human trafficking for both sexual and labour exploitation.

Keywords: crime, human trafficking, hotels, MAVUS, vulnerability studies 


\section{Introduction}

Trafficking in human beings (THB) is a form of modern slavery that is a rapidly growing global phenomenon (UNODC, 2016). THB involves the recruitment, transportation and the sexual or labour exploitation of vulnerable persons by force or coercion (Bales, 2003). Estimates of the extent of human trafficking vary enormously. The International Labour Organization identifies 21 million annual victims (ILO, 2014), whilst the Walk Free Foundation (2017) reports as many as 45.8 million victims. Whatever the real figure, this gross violation of human rights affects most countries around the world (Interpol, 2017) despite the widespread introduction of legislation to criminalise it (UNODC, 2016).

Early efforts to combat THB mainly focussed on the identification and protection of vulnerable persons who might fall prey to traffickers (Salt, 2000; Van Impe, 2000). However, the growth of THB has spurred researchers to examine this crime as a business to investigate factors that influence supply of and demand for trafficked victims (DanailovaTrainor and Belser, 2006), the organisation and modes of operation of trafficked networks (Surtees, 2008) and the motivation of traffickers (Shelley, 2010). Researchers have also recognised the role of legitimate businesses in conducting crimes (Vander Beken and Van Daele, 2008) and the characteristics of different industry sectors and their environments that makes them vulnerable to criminal activity (Klima, 2011; Mackenzie, 2011; Van Daele et al., 2007).

The hospitality industry has been identified as a sector vulnerable to the crime of THB. Hotels in particular provide a venue for traffickers to sexually exploit victims although evidence suggests that they are also used for labour exploitation (Annison, 2013; Armstrong, 2016; Robinson, 2013; Tuppen, 2013). While there are numerous, commendable anti-THB 
initiatives such as the Code of Conduct for the Protection of Children from Sexual Exploitation in Travel and Tourism (Rice, 2014), high profile cases of trafficking in global hotel chains in the UK, US and China (BBC, 2010; ECPAT International, 2011; Bhandari, 2010), demonstrate the sector remains vulnerable to this crime. Statistics published by the US National Human Trafficking Hotline (NHTH, 2016) reveal 10.5\% of sexual exploitation cases reported involved hotels, making this sector only less popular than commercial brothels.

Extant research examining child sex tourism (CST) and child sexual exploitation (CSE) has identified current prevention practices in tourism (Richter, 2005; Tepelus, 2008) and within the hotel sector (Kalargyrou, 2015). The rationale for, and consequences of, the use of illegal and trafficked labour within the restaurant sector has also been investigated (Hjalager, 2008). Researchers have also highlighted the potential for mega events to provide opportunities for sex trafficking (Tavela, 2008; Matheson and Finkel, 2013). While these studies highlight factors that influence hotel vulnerability, thus far there is no comprehensive empirical study of the environmental and industry characteristics that make the hotel sector vulnerable to THB crimes. This paper therefore reports on research that sought to address this gap and answers calls for research on the role of the private sector to help combat THB (Friesendorf, 2007; Rogoz et al., 2016).

The research was conducted as part of a wider European project funded by the European Commission's Directorate of Home Affairs under the Internal Security Fund's targeted call for Trafficking of Human Beings (THB). We report the findings related to one objective of the project: to identify and analyse the sector vulnerabilities that human traffickers exploit in order to use hotels as conduits of THB. The study makes three distinct contributions to the 
literature. It is the first empirical study to offer a systematic mapping of the macro-, mesoand micro-level factors that influence the growth of THB and create opportunities for traffickers to exploit their victims within hotels. Secondly, it identifies specific meso- and micro-industry characteristics that enhance the vulnerability for sex trafficking, labour trafficking or both, providing insight into the types of trafficking that occur. Thirdly, it develops a sector-specific framework for hoteliers to assess their vulnerability to THB.

The article begins by defining and identifying the current challenges faced in combatting THB. It then considers the extant sector vulnerability research to develop a framework of analysis for the hotel sector. The research design and findings are then presented before a hotel industry framework which depicts its vulnerabilities to THB. The conclusion reviews the contribution of the study, the implications for the industry and future research directions.

\section{Trafficking in Human Beings (THB)}

THB is a distinct criminal offence that is often confused with human smuggling of migrants (Tepelus, 2008). One of the most comprehensive definitions of THB, provided by the European Union (2011) is:

The recruitment, transportation, transfer, harbouring or reception of persons, including the exchange or transfer of control over those persons, by means of the threat or use of force or other forms of coercion, of abduction, of fraud, of deception, of the abuse of power or of a position of vulnerability or of the giving or receiving of payments or benefits to achieve the consent of a person having control over another person, for the purpose of exploitation.

(European Directive 2011/36/EU, Article 2) 
This definition identifies the three key stages of THB which distinguish it from human smuggling. In the recruitment stage, traffickers prey on some of the most vulnerable in society using coercion or deception (Kabance, 2014). In Europe, the 'lover boy' method, where traffickers assume the role of the victim's boyfriend, is most frequently used (Europol, 2016).

In the second stage, the movement of victims occurs both within and across country borders. In transnational $\mathrm{THB}$, victims originate from source countries and pass through transit countries to destination countries for the third stage of exploitation (Savona et al., 2013). Bulgaria, Hungary, Romania, Slovakia and Lithuania are the top EU source countries and Albania, Brazil, China, Nigeria and Vietnam the source of non-EU victims (Europol, 2016). Austria is a crucial transit country, especially for victims originating from Eastern Europe. Hungary is both a source country for Western Europe and destination country for Asian victims. Other destinations are spread across Western Europe and the majority of THB victims (71\%) registered in Europol's database in 2014 were EU citizens (Europol, 2016).

In the third stage, there are different types of exploitation which fall within the legal definition of THB including forced prostitution, labour, begging, criminality and marriage, domestic servitude, organ removal and illegal adoption (European Union, 2011). These three key stages clearly differentiate human trafficking from human smuggling. While both involve the recruitment and transport of victims, in the latter, smugglers move people illegally across international borders, generally for payment. As such, smuggling is a crime against the state, whereas trafficking is a crime against the person. However, smuggled victims are vulnerable in transit and destination countries and are thus susceptible to becoming trafficked victims (UNODC, 2017). 


\section{Current Challenges in Combatting THB}

According to Europol (2016), 90\% of the recorded THB cases in Europe were for sexual exploitation, $5.6 \%$ concerned labour exploitation, $1.9 \%$ forced marriages and $0.3 \%$ forced criminality and begging. As Eurostat (2015:30) reports 69\% of recorded cases to be sexual exploitation, and 19\% labour exploitation, the disparity in measuring the extent of this crime is evident. Anti-Slavery International (2017) advises that while sexual exploitation receives most attention, in reality there are more victims of labour exploitation. These statistics however, relate only to reported cases and most experts agree that these officially reported statistics are only the "tip of the iceberg" (Di Nicola, 2007:53). Eurostat (2015) identifies that there were only 30,146 victims officially reported between 2010 and 2012, a vastly different figure from the 1.14 million European victims estimated through research conducted by Datta and Bales (2013). Di Nicola (2007:53) argues that traffickers, victims and clients (end users of the victims) belong to "hidden populations" which are "neither easily identifiable nor easily found".

Identifying the true extent of trafficking therefore remains difficult and creates challenges in combatting THB. First, varying definitions, different reporting systems and different ways to record crimes in each country make the measurement of THB a very complex task (Salt, 2000). Second, law enforcement must determine whether victims have in fact been trafficked. McGaha and Evans (2009) maintain that victims are often employed legally or are considered accessories to crimes. Limited knowledge of THB and the identification of only what is easily recognisable (e.g. sexual exploitation) serve to skew reporting (De Nicola, 
2007). Third, these challenges are frequently exacerbated by limited resources to investigate trafficking incidents, as well as the presence of corrupt officials (Savona et al., 2013). Prosecution of traffickers is a fourth challenge, since trafficking victims are often either unwilling to report their situation (Hughes, 2000; Shelley, 2010) or testify in court (Surtees, 2008). Finally, identifying traffickers is challenging as there is no such thing as a typical trafficker (Surtees, 2008). Conviction rates of traffickers therefore remain lower than those for other serious crimes, even though THB is criminalised in 146 countries (UNODC, 2016). Accordingly, greater effort has been focussed on understanding the environment which enables THB to take place.

\section{Sector Vulnerabilities as Crime Enablers}

Researchers investigating modern slavery (including THB) have identified a number of macro-environmental factors that facilitate its growth. Bales (1999) proposed a theory of modern slavery based on social, cultural and economic factors. Subsequent testing of this theory revealed that the reduction in the price of slaves due to population growth; economic change (and the disparity between developed and emerging economies); and increased levels of corruption supported the growth of THB (Bales, 2006).

More recently, Crane (2013) drew on strategic capabilities and institutional theory to identify specific characteristics within industrial, socio-economic, geographic, cultural and regulatory contexts that enable modern slavery. For example, industrial characteristics include elasticity of demand and labour intensity, socio-economic contexts include levels of poverty and education and cultural contexts include religious beliefs. If traffickers possess the right capabilities, these factors enable them to deploy their activities as "management practice [...] despite widespread illegality and public opprobrium" (Crane, 2013:52). 
Criminology researchers have also recognised that crime prevention requires greater attention to be paid to the broader setting in which it takes place (Askola, 2007; Cree, 2008; Isgro et al., 2013). Several 'sector vulnerability' scholars maintain that to understand the risks of crime in specific markets, the characteristics of these markets must first be understood (Albanese, 2008; Vander Beken, et al, 2005). Bucquoye et al. (2005) advise that the criminal roles within a sector can be distinguished as victim, perpetrator, accomplice or facilitator. As legitimate businesses are often interconnected with criminal businesses, they can knowingly be active participants (perpetrator or accomplice) or unknowing conduits (victim or facilitator) for illegal activity (Vander Beken and Van Daele, 2008). These authors suggest that involvement of legitimate business can be explained through the policy of toleration within the sector, where criminal activity is considered the norm. Vaughan (1999:273-274) refers to this practice as 'social normalisation of deviance', where organisations and people become so accustomed to a deviant behaviour they don't consider it as such.

Sector vulnerability can be determined by assessing macro-environmental characteristics and the ways vulnerability is addressed by management. Albanese (2008) was the first to develop a 10 -factor framework to assess crime threat levels in a market based on four types of indicators: supply indicators (product/service availability, ease of movement); demand indicators (current demand and elasticity of demand); regulation indicators (ease of market entry, law enforcement capability); and competition indicators (history of crime in market, profitability, and impact of harm produced). While crime threat might change over time (Albanese, 2008), understanding the vulnerabilities of different economic or industry sectors within geographic locations is important for crime prevention (Vander Beken et al., 2005. To assess vulnerability, Vander Beken et al., (2005) developed a method for scanning economic 
sectors to identify potential points of victimisation titled "Method for the Assessment of the Vulnerability of Sectors" (MAVUS), applying it to waste management, transport and music sectors (Dorn et al., 2007; Van Daele et al., 2007; Vander Beken et al., 2005).

MAVUS is a mapping process, akin to environmental scanning, for sectors to identify opportunities that might be exploited and lead to crime. It includes analyses at the macro-, meso-and micro-levels. A scan of the macro-environment is conducted to determine relevant trends that affect regulation and competition, consumer demand, productivity and labour relations. The meso-level analysis focuses on two aspects: sector features (concentration, barriers to entry) and market features (business models, market structures, pricing, access to qualified labour). At micro-level, the analysis focuses on the organisational culture and operational aspects of organisations, including procurement, sales, financial administration, personnel management, technology and operations. Van Daele et al. (2007) assert that this framework of analysis is effective because it looks at the causes of crime within the context of the regulatory and economic environment where it takes place. Moreover, they argue that since it does not rely on official crime data, it does not replicate any "blind spots related with those data" and, by looking at current trends, it enables the detection of thus far "unrecognised and unreported crime risks" (p. 34).

\section{Hotel Sector Vulnerability}

As previously reported, the hotel sector has been identified as particularly vulnerable to THB (Annison, 2013; Armstrong, 2016; Robinson, 2013; Tuppen, 2013). In identifying legislative gaps that influence CSE, Smith (2010-2011) highlighted the relevance of the macroenvironment and argued the hotel sector is a facilitator of this crime. Previous research also points to the relevance of meso-level characteristics such as labour intensity, demand 
elasticity, and value distribution, all characteristics associated with the hotel sector, which further increase vulnerability (Crane, 2013). Additionally, mega events have also been shown to create opportunities for traffickers (Tavela, 2008; Matheson and Finkel, 2013). However, while previous research points to the relevance of macro-and meso-level factors, there appears to be limited research that investigates micro-level characteristics. Additionally, there is no published study that comprehensively identifies and analyses the sector vulnerabilities at all three levels that human traffickers exploit to use hotels as conduits of THB. As MAVUS has been used successfully in other sectors for other crimes, it was deemed a suitable framework to answer the following research questions:

- What are the environmental factors (macro-level) that provide opportunities for THB in the hotel sector?

- What are the hotel sector characteristics (meso-level) that make it vulnerable to THB?

- What are the hotel unit characteristics (micro-level) that make it vulnerable to THB?

\section{Research Design}

As part of a wider EC-funded project aiming to propose ways to combat THB in the hotel sector, Europe served as the research context where data collection focussed on four regions: Central and Eastern Europe, Northern Europe, Western Europe and Southern Europe. Each of the four project partners (two in UK, one in Finland and one in Romania) was assigned with a specific region. The data sources for the study included (Vander Beken et al., 2005) statistics about the sector (e.g., size in terms of rooms, number of people employed, size of key hotel groups, room demand and supply); secondary research on THB in Europe (academic literature, police and NGO reports, GRETA ${ }^{1}$ reports, etc.); expert advice (from the project's advisory board with experience in combating THB and

\footnotetext{
${ }^{1}$ GRETA: The Council of Europe's Group of Experts on Action against Trafficking in Human Beings http://www.coe.int/en/web/anti-human-trafficking/greta
} 
understanding of the hotel sector); and semi-structured interviews with key stakeholder informants in the project partners' countries.

To ensure uniformity of data collection and increase the quality of the study, guidelines were issued for conducting both secondary and primary research. The participants were identified using a non-probability, convenience sampling approach (Altinay et al., 2016) and a combined purposive and snowball technique. The research sought to examine human trafficking from three perspectives: that of the victim, law enforcement and the hotel business. Informants were therefore selected from these three areas based on their understanding and experience with THB as a crime and their professional standing at national and international levels (e.g., those with corporate responsibility within hotel groups, hotel and tourism professional associations, THB-specialised NGOs, trade unions, government and law enforcement officials) as depicted in Table 1. The interviewees were asked their views on the extent to which THB takes place in the sector and to give examples of THB cases they were aware of. They were also asked to explain how and why, in their opinion, particular properties were vulnerable to these incidents. The interview schedule was developed in English, then translated and back translated into each partner's language to ensure translational equivalence (Usunier, 2011).

In total, 29 semi-structured interviews each lasting up to one hour were conducted by trained interviewers from April to September 2015 in all three countries in the partners' local language. The digital recordings were transcribed, anonymised, member-checked and then analysed by the partners in their respective languages. Interviewees were coded according to their professional role (e.g., interviewees representing an anti-THB NGO would be coded as NC1, NC2, .., NC6, sector stakeholders ST1, ST2, ST3, etc.). 
Following the guidelines issued at the outset of the study, the analysis of the anonymised transcripts drew on the framework analysis approach developed for applied policy research (Ritchie and Spencer, 1994). It involves five interconnected stages of: familiarisation through review and reading; identification of a thematic framework; indexing; charting; mapping and interpretation (Ritchie et al., 2013).

\section{Insert Table 1 here}

The development of the thematic framework started at the familiarisation stage when the transcripts were coded. The researchers identified emerging themes using "both logical and intuitive thinking [...] making judgements about meaning, the relevance and importance of issues, and implicit connections about ideas' to ensure that the research questions are fully addressed" (Ritchie and Spencer, 1994: 180). The framework was then applied to the data (indexing) using textual codes (categories) to identify quotes to link to identified themes. Further codes were then developed under each of the main themes, thus refining the thematic framework. At this stage, a member of the advisory board was also involved in each country to ensure inter-rater reliability (Ritchie et al., 2013). The results of the thematic analysis were then organised into these different themes and matched with the MAVUS framework (charting). The mapping process allowed the visual display of the themes and the relevant data as well as the interpretations of the findings. At this final stage, the results were translated into English by professional translators and shared with the partners for data consolidation (Usinier, 2011). The consolidation of the data in the mapping process yielded a number of factors presented in the following section.

\section{Findings and Discussion}


The study revealed different types of THB occurring within the hotel industry as depicted in Table 2. The specific factors that influenced the vulnerability of hotels to these different types of THB at the macro-, meso- and micro-levels are identified in the following sections.

\section{Insert Table 2 here}

\section{Macro-level Factors}

At the macro-level, political, legal, economic and socio-cultural factors were identified to increase the opportunities for traffickers for both sexual and labour exploitation in Europe. Two political factors were found to heavily influence the growth of THB; the current refugee crisis in Europe and the inability of European states to protect their borders. The refugee crisis in Europe has become a new supply source for traffickers, thus exacerbating the exposure of the hotel sector to THB. Human traffickers take advantage of the thousands of civil war refugees, political asylum-seekers and economic migrants that are flooding Turkey and North Africa. The International Organisation for Migration reports that $71 \%$ of migrants attempting to cross the Mediterranean have experienced exploitation and those smuggled via North Africa are between seven and 10 times more likely to be trafficked than those reaching Europe from Turkey (IOM, 2016). NC3 who has worked with THB survivors trafficked via Libya said:

"African migrants following this Central Mediterranean route fall prey to human traffickers much easier than the Syrian refugees who choose this route. It is probably because they spend more time in transit with their 'minders' and they become their slaves way before the crossing to Europe. They are normally low- 
skilled persons and those who make it are used in the sex trade, agriculture, domestic or cleaning services and sale of counterfeit goods. One way or another, they are very likely to be exploited in the hotel sector". (NC3)

There is also evidence of an increase in child trafficking. Europol reports that in 2015, 5,000 children had disappeared in Italy, 1,000 were unaccounted for in Sweden and overall 10,000 refugee children were 'off-the-radar' (Townsend, 2016), a phenomenon attributed to a sophisticated pan-European criminal infrastructure targeting refugees. McClenaghan and McVeigh (2015) report that more than 900 asylum-seeking children have gone missing in the past five years in the UK, speculating that many have been trafficked for domestic servitude, forced begging or the sex trade.

The inability of European countries in the Schengen area to protect their borders also encourages THB. Trafficked victims only need a tourist visa to move across borders if they are not EU citizens and thus can be moved under a veil of legitimacy as tourists. Even when border agencies are tightening immigration controls the traffickers can easily re-route their victims. LE1 argues that:

'Even in the case of 'harder' border controls there is always the danger that officers focus more on identifying as many illegal immigrants as possible rather than trafficked victims. This way, they may not observe tell-tale indicators of victimhood or signalling types of behaviour because they focus on the verification of travel documents and the credibility of the travellers' stories. Trafficked victims 
identified as mere illegal immigrants may be deported but they will most certainly be re-trafficked”. (LE1)

This inability to control transnational movement of victims is also attributed to corrupt officials who illicitly issue and sell identity documents, visas and work permits (UNODC, 2011). NC4, LE2 and SS1 also reported that it is not unusual, particularly in certain Balkan and Eastern European countries, for members of the police force to not only allow THB, but to actively facilitate it as part owners of bars or nightclubs offering the sexual services of trafficked victims, receiving these sexual services, working as security guards, offering protection, and tipping-off owners about imminent police raids and document checks. Savona et al., (2013) previously identified that corrupt officials' impact on victims' reporting trafficking crimes. This study explains that finding by identifying the different types of roles corrupt officials play in THB.

Legally, THB is dealt with by numerous agencies even within the same country, leading to multiple interpretations of already diverse legislation and, as a consequence, to underreporting and low numbers of convictions. Despite efforts to align the regulatory and reporting framework across Europe with the anti-trafficking Directive 2011/36/EU, NC1, a legal expert, advises that: "the objective that the legal differences will be somehow remedied and that reporting will be aligned so that we can get a clearer picture is far too ambitious". Indeed, since the Directive's launch, the EC reports that there were less registered THB victims than previously, "due to possible differences in recording methods and legal definitions" (EC, 2016:5). 
The economic disparity between European countries and between Europe and source countries where poverty is increasing provide further opportunities for THB with victims more susceptible to deception and the promise of a better life (Crane, 2013). This same disparity also exists in the 'shadow economy', i.e., legal business activities performed outside governments' reach (HI4, HI5, TI2, ST3) which is predicted to increase in Austria, Belgium, France, Hungary, Luxembourg and Malta (Schneider, 2015). Undeclared work accounts for roughly two-thirds of the shadow economy reflecting a trend for many employers and employees not to report wages to avoid tax and other contributions (Schneider 2013). Undeclared work has been identified as a particularly common characteristic of small business in the hotel (EASHW, 2008) and restaurant sectors (Hjalager, 2007), providing a clear opportunity for labour exploitation.

Socio-culturally, a worrying trend of exploitation rationalisation was highlighted by seven interviewees who reported that within their professional circles, more people thought there was nothing wrong with the prostitution, sexual and labour exploitation of immigrants. Interviewees reported:

"There are quite a few people out there who believe that this is OK! They reject what they call 'label of victim' and say that when [the victims] were in their countries they did not have anything to eat and they would do anything just to get some food ... Now, at least they have some money, a roof over their heads, clothes, underwear ..."

(HI3) 
“... there is a prevalent idea that these girls 'had it coming' because they either have an addiction or they like the luxury lifestyle. And everyone is happy! The pimps take their money, the bars take their money, the hotels take their money and the 'johns' take the satisfaction ... And the girls? They get paid and sometimes they even enjoy sex!” (TI2)

Clearly, part of society does not distinguish between voluntary and forced prostitution, probably unaware that $60-70 \%$ of the prostitution today is forced by criminal groups (Schulze et al., 2014). It also appears that many people (among them some hotel professionals) are shifting from 'social normalisation of deviance' (Vaughan, 1999), where the individual still feels uncomfortable with a deviant behaviour, to outright rationalisation and 'neutralisation' (Sykes and Matza, 1957), where the individual finds a criminal activity perfectly acceptable and rationally justifiable. Sykes and Matza (1957) state that this 'neutralised' behaviour is observed in people who wish to guard against any feelings of guilt when they have committed a crime or are accessories to a crime.

\section{Meso-level Factors}

At the meso-level, specific characteristics of the industry and its value chain influence hotel vulnerability to THB. Some characteristics however, increase vulnerability to sex trafficking, some to labour and some to both.

The fragmented and diverse nature of the hotel sector constitute key vulnerabilities to both types of exploitation according to the interviewees. HI8 argued that "that there are far too many players to co-ordinate in this combat [against THB] and you will always find some bad apples who will spoil the bunch". The geographic dispersion and isolation 
(Crane, 2013) of hotels make them more attractive to traffickers and perhaps easier for rogue hoteliers to neutralise any form of exploitation within their premises. Even where the sector is more consolidated with branded hotel groups, "our [asset-light] business model makes it harder to implement a strict anti-THB policy throughout our estate as we can control our owned and managed portfolio but have little influence over our franchisees" (HI2). TI2 offered a rather pessimistic outlook saying "we are supposed to be an industry of happiness but even if we try very hard to fight [human] trafficking we will only manage to displace it to smaller hotels, rental apartments or Airbnb. There, nobody can control traffickers and what they do".

A changing criminal market structure is another characteristic increasing the vulnerability to both types of THB. While the literature (e.g., Albanese, 2008; Aronowitz et al., 2010; Surtees, 2008; UNODC, 2016) identifies human traffickers organised in sophisticated criminal groups usually associated with their country of origin, interviewees in this study (LE2, LE3, SS1, SS2) suggested that the 'market' has changed, reporting:

"The THB market in the past few years has been disrupted by a large number of new entrants who were mostly opportunists that wanted to make a quick buck. Just 'grab-and-go' strategies, very short-term outlook, bringing the bar too low. Some of them were driven out - sometimes forcefully - but their impact remains and, given that there is a steady demand, the bar will remain low". $(\mathrm{SS} 1)$ 
This change in the 'market structure' has driven down the cost of trafficked victims and reduced market entry barriers for smaller opportunistic traffickers with local market knowledge (Van Daele et al., 2007).

Three other important hotel sector characteristics influence labour exploitation specifically: labour intensity, low profit margins and business seasonality. HI6 advised, "you cannot run hotels without staff and this [labour] is the highest operational cost you have. You need staff in certain periods a day and certain times of the week or the year. With the margins you are allowed, you have to make tough decisions". This interviewee only implied what others (HI3, HI4, HI7) brought up as issues for the sector: the employment of agency staff and shadow labour. Both practices provide opportunities for traffickers to supply labour victims, either directly or indirectly through legitimate, or seemingly legitimate, recruitment agencies (Aronowitz et al., 2010; Shelley, 2014). ST1 reported that employment practices in the sector can often be "a recipe for disaster" with regards to human trafficking, commenting:

“... with the image that hoteliers have in the eyes of the public when it comes to zero-hour contracts, wages, agency staff and tips [service charges] not given to the staff, it is not surprising that they don't recognise it [human trafficking] as an industry problem; they don't want to admit to it." (ST1)

HI3 pointed out that the use of "alternative labour supply sources" and the general lack of labour inspection for employment standards, combined with low trade union representation in most European countries allow certain hoteliers to "interpret employment standards in a more 'flexible' way, thus opening the door to all sorts of 
agents who may very well be traffickers". HI5 argued that when hotels are using agencies, they practically surrender all candidate vetting to them. When hotels are hiring staff needing work permits, the exposure to traffickers is greater since, as agents, they usually keep control of all the relevant documentation and, as a result, the candidates themselves. MC6 recognised that today many hotels are practically run with only migrant employees and warned that the employment of a very culturallydiverse workforce may cause communication barriers, making it difficult for the victims to communicate their situation.

Interviewees also identified food and linen suppliers and construction companies as other sectors that may contribute to hotel sector vulnerability. There are many documented cases (Aronowitz et al., 2010; Shelley, 2010; Surtees, 2008, Van Impe, 2000) where these sectors have used labour victims or been conduits of trafficking to other sectors. ST1 suggested that trade unions have a great potential to be a "power of good" in the fight against THB, while HI3 suggested that customers ("customer base") should be considered an influential group as they determine with their bargaining power, to an extent, the way that business is conducted.

\section{Micro-level Factors}

At the micro-level, interviewees identified numerous factors related to individual company business practices. As with the meso-level, some of these increased hotel vulnerability to sexual exploitation, some to labour exploitation and some to both. Most interviewees pointed out that different hotel companies have different organisational cultures and this should be the starting point of any vulnerability discussion. Although "ethical conduct" and "business ethics" were mentioned by all interviewees as a core 
element of organisational culture that influences THB, it was not always the case "realistically" (HI2, HI4, HI5) or "in reality” (HI1, HI7). As such, there is a disparity between intent and action as dictated by commercial and other pressures of the business environment.

HI8 stated that "[any tolerance of prostitution] is a misconstrued interpretation of the discreetness and hospitality we are claiming to offer - it is not customer orientation". HI2 suggested that a zero-tolerance approach to THB should be the cornerstone of the fight. However, when prompted, she admitted that ("realistically") only in owned and managed properties can this be implemented "with some effect" - the franchise model is more challenging. The effectiveness of policy implementation even in managed properties can also be questioned. MC4 reported on a managed property, of a hotel group that is a signatory of the Code, in which minors are knocking on guestroom doors to offer their sexual services. SS1 admitted that although he has worked with many companies that are recognised as the most ethical in the sector, he has encountered properties where sexual services of escorts (possibly trafficked persons) were offered by the front desk on a commission basis. This practice reflects professionals moving beyond 'social normalisation' to 'neutralisation'. In some countries, this is perfectly acceptable business behaviour whereas in others, this practice could lead to the hotel being prosecuted as an accomplice to THB. Furthermore, there is growing pressure for businesses to be deemed legally culpable in THB offences, even if not complicit. Additionally, victims are becoming more inclined to bring civil lawsuits against businesses (Lawrence, 2016). 
There are, however, hotels that offer in-house escort services in order to protect their guests. SS3 brought the example of an international hotel group's property which made the decision to officially adopt an in-house escort service with vetted prostitutes, as it was experiencing a high number of "cold departures" (guests who died in their rooms from excess use of alcohol and drugs or after being mugged) after street prostitutes were brought into the hotel. From the hotel's perspective, they were just protecting their guests.

HI2 and HI3 admitted that sometimes the pursuit of 'pipeline' portfolio growth supersedes the due diligence that companies show in selecting hotel owners they will work with. Some interviewees (HI4, TI2, SS3) admitted that a strong sales-orientation culture can be detrimental to the fight against THB as it may cause moral dilemmas to hotel managers. MC4 suggested that, despite these commercial challenges, "hotels should seek to develop an anti-trafficking culture which should be stronger than any customer or sales-performance orientation”.

Technology significantly increases property-level vulnerability to sexual exploitation. Traffickers advertise and distribute the services of women and children through the internet, with photos taken in hotel rooms. HI2 reported that traffickers are taking advantage of automated reservation systems to obtain confirmations of bookings they make (and later cancel) to obtain tourist visas for their trafficked victims. HI5 advised that with smartphones being used to check-in and as room-keys, the hotel risks losing control of who is actually in the guestroom. HI7 also noted that in many budget hotels the technology allows a guest to check-in and out without any encounter with the hotel staff. HI2 suggested that any technological progress should be embraced, but thought 
should be given to how it can be used as a tool against the traffickers "who leave their traces when they use it”.

From an operational perspective, procurement and employment practices dominated answers on vulnerability to labour exploitation. Most revolved around vetting agencies, audits of tier-1 suppliers (primarily of food and linen products) and background checks of newly recruited employees. However, the business model of franchising was identified again as a potential barrier to reducing vulnerability and the extra cost of adding protective measures was highlighted by HI6 and HI7.

Financial administration practices, mostly in relation to payments made to agencies, suppliers and employees, were also identified as factors increasing vulnerability to labour trafficking. Interviewees suggested that an audit trail should be established to ensure that the payments reach the appropriate entities and persons via legitimate accounts. HI4 suggested that cash payments are a potential 'red flag' for criminal activity and should be avoided, especially when the hotel is receiving the payment. Financial controls need to be robust as hotels may become targets of organised criminals that may place trafficked persons as full-time employees in hotels in order to commit fraud on their behalf. HI1 reported the case of a trafficked victim being placed in a hotel front office and tasked to register walk-in guests as having rooms reserved by the traffickers' travel agency in order for the traffickers to collect commissions. A robust employment practice combined with rigorous financial controls would have stopped this case of forced criminality at a much earlier stage. 
The level of training within a property is another factor that influences vulnerability to both types of THB. MC5 questioned the level of THB awareness at property level and the extent to which hotel personnel are trained to recognise signs of THB. She suggested that this requires full buy-in from the property's general manager regardless of size or affiliation. Training on what THB is, what it does to its victims, and specific signals in different operational departments were frequently mentioned by interviewees. Such training would instil the right anti-THB culture which, linked with a safe and trusted incident reporting system (MC3), robust financial policies and controls, (e.g., no cash payments accepted (HI4) and wise use of technology to trace identities of traffickers and victims (HI2) would constitute a sufficient defence mechanism against THB in a hotel.

This MAVUS analysis enabled a framework of hotel sector vulnerability to be developed as depicted in Figure 1.

\section{Fig. 1 - A MAVUS Framework for the Hotel Sector's Vulnerability to Human Trafficking}

\section{Insert Figure 1 here}

\section{Conclusions}

This study sought to contribute to our understanding of THB within the hotel industry by analysing hotel sector vulnerability. Using the MAVUS framework, it adopted a systematic approach to identify environmental factors that create opportunities for traffickers and industry characteristics which facilitate exploitation of victims within hotels. In answering the three research questions posed, the study also identified a 
number of different types of THB occurring within the industry and the macro-, mesoand micro-level factors that contribute to hotel vulnerability.

\begin{abstract}
At the macro-level, political (extensive immigration, weak border controls), regulatory (varying legal frameworks and definitions, widespread corruption), economic (economic disparity, increasing poverty, shadow economy) and socio-cultural (societal normalisation of deviance) factors create opportunities for trafficking for both sexual and labour exploitation. Economic factors increase the vulnerability and supply of victims, and political and regulatory facilitate the transport and movement of victims. Regulatory factors as well as the specific socio-cultural factor of "normalisation of deviance' (especially when it comes to sexual exploitation) underpin the acceptance of THB and help to explain the growth of this criminal activity. While these macro-level factors are not hotel-specific, they do influence sector vulnerability when combined with meso- and micro-level industry characteristics.
\end{abstract}

At the meso-level, the study revealed that the fragmented and diverse nature of the hotel industry, the business models adopted by large corporate hotel groups (pipeline growth through asset-light models with limited control over franchisees) and the changing market structure for traffickers, increase the likelihood that hotels will be used as vehicles for sexual and labour exploitation. Business seasonality, labour intensity and low profitability further increase vulnerability to labour exploitation. Together these meso factors increase the chances of hotels becoming facilitators of THB. Additionally, the study demonstrates that the sector cannot be effective in combating THB alone; rather collaboration with trade unions, suppliers, construction companies and recruitment and outsourcing agencies is required. 
The study also revealed that the fundamental starting point for combating THB is at the micro-level and the culture of the organisation. The findings suggest a customer- and sales-orientation (often exacerbated by the business models employed) prioritised over moral and ethical decisions, drive unit-level operational practices that increase exposure to both types of THB. These practices, in turn, further shape the organisational culture within hotels and determine whether or not an anti-trafficking culture can be effectively implemented.

Technology and in particular the automation of operational practices (e.g., automated reservation and check-in systems) increase vulnerability to sexual exploitation whereas practices related to employment, procurement and financial management increase vulnerability to labour exploitation. A lack of training was also shown to increase hotel vulnerability to all types of THB.

Weak operational practices not only increase the risk of hotels becoming victims of THB crime, but also facilitators or willing accomplices. As a victim, hotels face financial risks. As a facilitator, hotels run the risk of being deemed culpable in a crime, even if they were not complicit and they potentially face civil liabilities for their involvement. As an accomplice, hotels risk being specifically implicated in a criminal activity. Whatever role hotels play, they also risk damaging industry and brand reputation amongst customers and other stakeholders and operational disruption if implicated in a crime. They also have moral obligations to protect victims that are trafficked within their properties and to help law enforcement to combat this crime. 


\section{Theoretical Implications}

This study also makes a theoretical contribution by identifying the applicability of criminology theories to business sectors vulnerable to THB and other criminal activities. Through the application of an integrated theoretical lens drawing on environmental scanning and theories of environmental criminology, the study identifies that in the presence of certain macro environmental variables, meso-level and industry-specific characteristics can enhance vulnerability to crime, in this case either vulnerability to THB for sexual or labour exploitation.

\section{Practical Implications}

The study therefore has clear implications for hotels, whether independent or chainaffiliated, as it highlights the need to recognise and take the necessary precautions to reduce their vulnerability to THB and mitigate its risks. The hotel-specific MAVUS framework developed provides a structured approach for hotel professionals to assess their own organisation's vulnerability to THB at the meso- and micro- level, while considering the broader macro-environment in which they operate. Additionally, it points to the importance of organisational culture in any anti-THB initiatives. While competition will continue to drive customer and sales orientations, moral and ethical obligations for THB victims should not be overlooked, given the range of potential risks faced by hotels. The findings presented in this study also point to specific operational activities that can assist in reducing hotel vulnerability to THB and in meeting ethical and moral obligations towards law enforcement and victims.

\section{Limitations and Future Research}

The study, however, is not without limitations. The small sample size and the three European country context limit its generalisability. While the study provides a 
comprehensive overview of hotel vulnerability to THB without official reporting 'blind spots', further research is needed to identify the full extent of TBH occurring within the sector using a larger and more geographically disperse sample. Additionally, research to identify how THB can be prevented in hotels and the specific policies and practices that can disable traffickers from exploiting their victims for both sexual and labour purposes is required. Further research is also warranted on management control systems that could be used to effectively implement an anti-THB strategy and on how hotels can work collaboratively within their supply chain networks to combat THB. 


\section{References}

Albanese, J. (2000), “The Causes of Organized Crime”, Journal of Contemporary Criminal Justice, Vol. 16 No 4, pp.409-423.

Albanese, J. (2008), "Risk Assessment in Organized Crime: Developing a Market and Product-Based Model to Determine Threat Levels", Journal of Contemporary Criminal Justice, Vol. 24 No 3, pp. 263-273.

Altinay, L., Paraskevas. A. and Jang, S. (2016), Planning research in hospitality and tourism, 2nd edition, London: Routledge

Annison, R. (2013), Hidden in plain sight: Three years on: updated analysis of UK measures to protect trafficked persons, The Anti-Trafficking Monitoring Group, available at:

http://www.antislavery.org/includes/documents/cm docs/2013/h/hidden_in_plain_sight.pdf (accessed 28 January 2015).

Armstrong, R., (2016), "Modern Slavery: Risks for the UK Hospitality Industry" in Goodwin, H. and Font, X. (Eds.) Progress in Responsible Tourism V, Goodfellow Publishers Ltd., Oxford, pp. 67-78.

Aronowitz, A., Theuermann, G. and Tyurykanova, E. (2010), Analysing the business model of trafficking in human beings to better prevent the crime, Office of the Special Representative and Co-ordinator for Combating Trafficking in Human Beings available at: http://www.osce.org/files/documents/c/f/69028.pdf (accessed 9 January 2017).

Bales, K. (1999), Disposable people: new slavery in the global economy, University of California Press Berkeley, California.

Bales, K. (2003), Understanding the demand behind human trafficking, National Institute of Justice, Washington, DC.

Bales, K. (2006), Testing a theory of modern slavery, Free the Slaves, available at: http://lastradainternational.org/lsidocs/bales test theory 0607.pdf (accessed 15 January, 2017).

BBC (2010), "Jail for Gang Offering Sex with Trafficked Women", BBC News, 14 September, available at: http://www.bbc.co.uk/news/uk-england-london-11305510 (accessed 12 March 2017).

Bhandari, M. (2010), "Hilton Worldwide Responds to Child-Trafficking Scandal", Washington Business Journal, 1 November, available at:

http://www.bizjournals.com/washington/news/2010/10/31/hilton-responds-to-childtrafficking.html (accessed 15 March 2017).

Bucquoye, A., Verposet, K., Defruytier, M. and Vander Beken, T. (2005), "European Road Transport of Goods", in Vander Beken, T. (Ed.), Organised crime and vulnerability of economic sectors: the European transport and music sector, Maklu Publishers, Antwerp, pp. 57-193. 
Crane, A. (2013), "Modern Slavery as a Management Practice: Exploring the Conditions and Capabilities for Human Exploitation", Academy of Management Review, Vol. 38 No. 1, pp.49-68.

Danailova-Trainor, G. and Belser, P., (2006), Globalization and the illicit market for human trafficking: an empirical analysis of supply and demand, Geneva: ILO.

Datta, M. and Bales, K. (2013), "Slavery in Europe: Part 1, Estimating the Dark Figure". Human Rights Quarterly, Vol. 35 No. 4, pp. 817-829.

Di Nicola, A. (2007), "Researching into Human Trafficking: Issues and Problems" In M. Lee (Ed.), Human Trafficking, Cullompton, UK: Willan, pp. 49-72.

Dorn, N., Van Daele, S. and Vander Beken, T. (2007), "Reducing Vulnerabilities to Crime of the European Waste Management Industry: The Research Base and the Prospects for Policy", European Journal of Crime, Vol. 15 No. 1, pp. 23-36.

ECPAT International, (2011), "Second Gang Busted for Child Sex Trafficking at Wyndham Hotel", News Clippings, available at:

http://www.ecpatinternational.com/EI/Resource newsclippings.asp?id=1203 (accessed 29 March 2017).

EASHW (2008), Protecting workers in hotels, restaurants and catering, Luxembourg: European Agency for Safety and Health at Work.

European Commission (2016), Report on the progress made in the fight against trafficking in human beings, available at: http://ec.europa.eu/home-affairs/sites/homeaffairs/files/what-wedo/policies/organized-crime-and-human-trafficking/trafficking-in-humanbeings/docs/commission report on the progress made in the fight against trafficking in human beings 2016 en.pdf (accessed 31 March 2017).

European Union (2011), Directive 2011/36/EU of the European Parliament and of the Council on Preventing and Combating Trafficking in Human Beings and Protecting its Victims, Official Journal of the European Union, 5 April, available at: http://eurlex.europa.eu/legal-content/EN/TXT/HTML/?uri=CELEX:32011L0036\&from=EN (accessed 31 March 2017).

Europol (2016), Situation report: Trafficking in human beings in the EU, available at: https://ec.europa.eu/antitrafficking/sites/antitrafficking/files/situational_report trafficking_in human beingseuropol.pdf (accessed 12 March 2017).

Eurostat (2015), Trafficking in human beings, available at: https://ec.europa.eu/antitrafficking/sites/antitrafficking/files/eurostat report_on trafficking_in human beings _2015 edition.pdf (accessed 23 March 2017).

Hjalager, A.M. (2008), "The Illegal Economy in the Restaurant Sector in Denmark". Tourism and Hospitality Research, Vol. 8 No. 3, pp. 239-251. 
Hughes, D.M., (2000), “The 'Natasha' trade: The Transnational Shadow Market of Trafficking in Women”. Journal of International Affairs, Vol. 53 No. 2, pp. 625-651.

ILO (2014), Profits and poverty: The economics of forced labour, Geneva: International Labour Organization.

Interpol (2017), Trafficking in human beings, Fact sheet, available at: https://www.interpol.int/content/download/796/6455/version/35/file/13 THB02 02 2017_E N_web.pdf (accessed 30 March 2017).

IOM (2016), Analysis: Flow monitoring surveys - The human trafficking and other exploitative practices, Prevalence Indication Survey, Reporting Period June 2016 September 2016, Geneva: International Organisation for Migration.

Kalargyrou, V. and Woods, R. (2015), “An Exploratory Study of Child Commercial Sexual Exploitation in the Hospitality Industry in the United States", Hospitality and Society, Vol. 5 No. 1, pp.43-69.

Klima, N. (2011), “The Goods Transport Network's Vulnerability to Crime: Opportunities and Control Weaknesses". European Journal on Criminal Policy and Research, Vol. 17 No. 3, pp.203-219.

Lawrence, F. (2016). Court finds UK gangmaster liable for modern slavery victims Available at: https://www.theguardian.com/global-development/2016/jun/10/court-finds-ukgangmaster-liable-for-modern-slavery-victims-kent-chicken-catching-eggs (accessed 23 December 2016).

Mackenzie, S. (2011), "The Market as Criminal and Criminals in the Market: Reducing Opportunities for Organised Crime in the International Antiquities Market", in S. Manacorda and D. Chappell (eds.), Crime in the art and antiquities world: illegal trafficking in cultural property, Springer, New York, pp. 69-85.

Matheson, C.M. and Finkel, R. (2013), "Sex Trafficking and the Vancouver Winter Olympic Games: Perceptions and Preventative Measures”, Tourism Management, Vol. 36 No. 3, pp. 613-628.

McClenaghan, M. and McVeigh, T. (2015), "Fears over Increase in Asylum-Seeking Children who Go Missing after Arrival in UK”, The Observer, 5 December, available at: https:/www.theguardian.com/world/2015/dec/05/asylum-seeker-children-refugees-missing (accessed 6 February 2017).

McGaha, J. and Evans, A. (2009), "Where Are the Victims? The Credibility Gap in Human Trafficking Research", Intercultural Human Rights Law Review, Vol. 4, No 2., 239-266.

NHTH (2016), Hotline statistics by state, National Human Trafficking Hotline available at: https://humantraffickinghotline.org/states (accessed 30 March 2017).

Rice, K., (2014), “The War on Human Trafficking”, Travel Weekly, 7 May, available at: http://www.travelweekly.com/Travel-News/Travel-Agent-Issues/The-war-on-human- 
trafficking (accessed 1 April, 2017).

Richter, L. (2005), "Not a Minor Problem: Developing International Travel Policy for the Welfare of Children", Tourism Analysis, Vol. 10 No. 1, pp. 27-36.

Ritchie, J. and Spencer, L., (1994). "Qualitative data analysis for applied policy research", in Bryman, A. and Burgess, R. (Eds.), Analysing Qualitative Data. Routledge, London, pp. 173-194.

Ritchie, J., Lewis, J., Nicholls, C.M. and Ormston, R., (2013). Qualitative research practice: A guide for social science students and researchers. New York: Sage.

Robinson, R. (2013), "Darker Still: Present-day Slavery in Hospitality and Tourism Services”, Hospitality and Society, Vol. 3 No. 2, pp. 93-110.

Salt, J. (2000), "Trafficking and Human Smuggling: A European Perspective", International Migration, Vol. 38 No. 3, pp. 31-56.

Savona, E., Giommoni, L., and Mancuso, M. (2013), "Human Trafficking for Sexual Exploitation in Italy". In Leclerc, B. and Wortley, R. (Eds.), Cognition and Crime: offender decision-making and script analyses, Crime Science Series. Routledge, London, pp. 140-163.

Schneider, F. (2013), The shadow economy in Europe, AT Kearney, available at: http://www.atkearney.fr/documents/10192/1743816/The+Shadow+Economy+in+Europe +20 13.pdf (accessed 30 October 2015).

Schneider, F. (2015), Size and development of the shadow economy in Europe (2003-2015), Linz: Johannes Kepler University available at: http://www.econ.jku.at/members/Schneider/files/publications/2015/ShadEcEurope31.pdf (accessed 12 March 2017).

Schulze, E., Canto, S., Mason, P. and Skalin, M. (2014), Sexual exploitation and prostitution and its impact on gender equality. Study, European Parliament, DG for Internal Policies, available at: http://www.europarl.europa.eu/RegData/etudes/etudes/join/2014/493040/IPOLFEMM_ET(2014)493040_EN.pdf (accessed 18 January2017).

Shelley, L (2010), Human trafficking, Cambridge University Press, New York, NY.

Surtees, R. (2008), "Traffickers and Trafficking in Southern and Eastern Europe. Considering the Other Side of Human Trafficking", European Journal of Criminology, Vol. 5 No.1, pp. 539.

Sykes, G. and Matza, D. (1957), "Techniques of Neutralization: A Theory of Delinquency", American Sociological Review, Vol. 22 No. 6, pp.664-670.

Tepelus, C. (2008), "Social Responsibility and Innovation on Trafficking and Child Sex Tourism: Morphing of Practice into Sustainable Tourism Policies?", Tourism and Hospitality Research, Vol. 8 No. 2, pp. 98-115. 
Townsend, M. (2016), “10,000 Refugee Children Are Missing, Says Europol”, The Observer, 30 January, available at: https://www.theguardian.com/world/2016/jan/30/fears-for-missingchild-refugees (accessed 22 February 2017).

Tuppen, H., (2013), “Addressing Human Trafficking in the Hospitality Industry”, Green Hotelier, 18 July, Know How Guides, International Tourism Partnership, available at: http://www.greenhotelier.org/know-how-guides/addressing-human-trafficking-in-thehospitality-industry/ (accessed 8 December 2016).

UNODC (2011), The role of corruption in trafficking in persons, Issue Paper, United Nations Office on Drugs and Crime available at: https://www.unodc.org/documents/humantrafficking/2011/Issue_Paper_- The Role_of_Corruption_in_Trafficking_in_Persons.pdf (accessed 15 March 2017).

UNODC (2016), Global report on trafficking in persons, United Nations Office on Drugs and Crime available at: https://www.unodc.org/documents/data-andanalysis/glotip/2016_Global_Report_on_Trafficking_in_Persons.pdf (accessed 30 March 2017).

UNODC (2017) Trafficking in Persons and Migrant Smuggling downloaded from https://www.unodc.org/lpo-brazil/en/trafico-de-pessoas/index.html ( accessed 15 August, 2017)

Usunier, J.C., (2011). "Language as a Resource to Assess Cross-Cultural Equivalence in Quantitative Management Research”. Journal of World Business, Vol. 46, No.3, pp.314-319. Van Daele, S., Vander Beken, T. and Dorn, N. (2007), "Waste Management and CrimeRegulatory, Business and Product Vulnerabilities", Environmental Policy and Law, Vol. 37 No. 1, pp. 34-38.

Van Impe, K. (2000), "People for Sale: The Need for a Multidisciplinary Approach Towards Human Trafficking”, International Migration, Vol. 38 No. 3, pp.113-191.

Vander Beken, T. and Van Daele, S. (2008), "Legitimate businesses and crime vulnerabilities". International Journal of Social Economics, Vol. 35 No. 10, pp.739-750.

Vander Beken, T., Defruytier, M., Bucquoye, A. and Verpoest K. (2005), "Road Map for Vulnerability Studies," in Vander Beken, T. (Ed.), Organized crime and vulnerability of economic sectors: the European transport and music sector, Maklu Publishers, AntwerpApeldoorn, pp. 7-56.

Vaughan, D. (1999), "The Dark Side of Organizations: Mistake, Misconduct, and Disaster", Vol. 25 No. 1, pp. 271-305.

Walk Free Foundation (2017), Global Slavery Index available at: http://www.globalslaveryindex.org/ (accessed 01 April 2017). 
Table 1: Interviewees by Country

\begin{tabular}{|c|c|c|c|c|}
\hline $\begin{array}{c}\text { Stakeholder Sector and } \\
\text { Code }\end{array}$ & $\begin{array}{c}\text { United } \\
\text { Kingdom }\end{array}$ & Romania & Finland & Total \\
\hline Hotel Industry (HI) & 3 & 2 & 3 & 8 \\
\hline Tourism Industry (TI) & 1 & 1 & 1 & 3 \\
\hline Law Enforcement (LE) & 1 & 1 & 2 & 4 \\
\hline Security Services (SS) & 3 & 1 & 1 & 5 \\
\hline NGO / Charity (NC) & 1 & 3 & 1 & 3 \\
\hline Sector Stakeholder (ST) & 1 & 1 & $\mathbf{1 0}$ & $\mathbf{2 9}$ \\
\hline Total & $\mathbf{1 0}$ & $\mathbf{9}$ & \\
\hline
\end{tabular}


Table 2: Types of THB identified in the European Hotel Industry

\begin{tabular}{|l|l|}
\hline \multicolumn{1}{|c|}{ Type of THB } & \multicolumn{1}{c|}{ Definition } \\
\hline Forced Prostitution & $\begin{array}{l}\text { Involuntary prostitution, that takes place as a result of force or } \\
\text { coercion by a third party. }\end{array}$ \\
\hline $\begin{array}{l}\text { Child Sexual } \\
\text { Exploitation }\end{array}$ & $\begin{array}{l}\text { Sexual abuse of children under 18 years of age, including } \\
\text { prostitution, the production of sexual images, encouraging children to } \\
\text { behave in sexually inappropriate ways or grooming a child in } \\
\text { preparation for abuse. }\end{array}$ \\
\hline Forced Labour & $\begin{array}{l}\text { Persons forced to work through the use of violence or intimidation, or } \\
\text { by more subtle means such as retention of identity papers or threats } \\
\text { of denunciation to immigration authorities. }\end{array}$ \\
\hline Bonded Labour & $\begin{array}{l}\text { Persons forced to work to pay off a debt. They are tricked into } \\
\text { working for little or no pay, with no control over their debt. }\end{array}$ \\
\hline Forced Criminality & $\begin{array}{l}\text { Persons forced to commit a range of crimes, such as theft or fraud } \\
\text { against the hotel business. }\end{array}$ \\
\hline Domestic Servitude & $\begin{array}{l}\text { Persons forced to perform a range of tasks in the privacy of hotel } \\
\text { rooms as an extension to the private homes of the trafficker. }\end{array}$ \\
\hline $\begin{array}{l}\text { Forced labour in supply } \\
\text { chains and construction }\end{array}$ & $\begin{array}{l}\text { Persons forced to work through the use of violence or intimidation, or } \\
\text { by more subtle means in specific supply chain businesses or within } \\
\text { the construction of hotels. }\end{array}$ \\
\hline
\end{tabular}


Trafficking in Human Beings (THB)

- Forced Prostitution

Child Sexual Exploitation

- Forced/Bonded Labour

- Forced Criminality

- Domestic Servitude

- Forced labour in supply

chains and construction

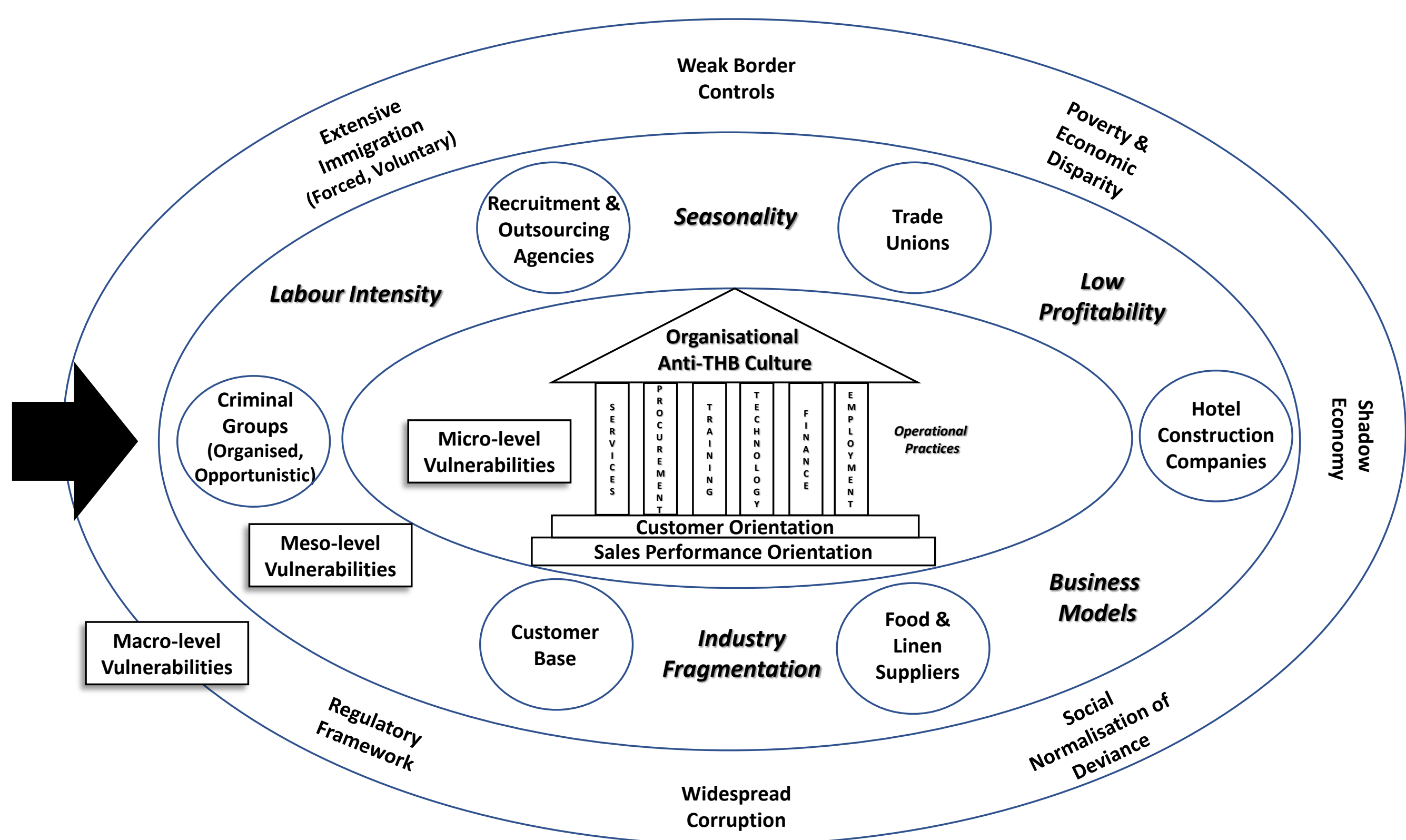

http://mc.manuscriptcentral.com/ijchm 